\title{
THE EFFECTS OF
}

INDOMETHACIN ON ARACHIDONIC ACID

AND PROSTAGLANDINS $E_{2}$ AND $F_{2 \alpha}$ LEVELS IN HUMAN SKIN 24 H AFTER u.v.B AND u.v.C IRRADIATION

\author{
A.K. BLACK, M.W. GREAVES, C.N. HENSBY, N.A. PLUMMER \& A.P. WARIN \\ Professorial Unit, Institute of Dermatology, Homerton Grove, London E9 6BX
}

1 Clinically normal human abdominal skin was irradiated with either three times its minimal erythema dose (MED) of ultraviolet B (u.v.B) or six MEDs of ultraviolet C (u.v.C) radiation. In both instances erythema was maximal at $24 \mathrm{~h}$.

2 Exudate was recovered by a suction bulla technique from normal and irradiated skin at $24 \mathrm{~h}$ after irradiation.

3 Arachidonic acid, prostaglandins $\mathrm{E}_{2}$ and $\mathrm{F}_{2 a}$, as measured by $\mathrm{GC}-\mathrm{MS}$, were significantly elevated at $24 \mathrm{~h}$. Radioimmunoassay also showed increased $\mathrm{PGF}_{2 a}$-like concentrations.

4 Oral indomethacin only partially reduced the erythema resulting from both types of radiation but totally suppressed the elevation of $\mathrm{PGE}_{2}$ and $\mathrm{F}_{2 a}$ concentrations.

5 Topical indomethacin also suppressed u.v.B-induced increases in prostaglandins $E_{2}$ and $F_{2 a}$. Unexpectedly, the vehicle alone produced a similar suppressive effect on prostaglandins although erythema appeared unaltered.

6 Most of the arachidonic acid metabolized by indomethacin-sensitive pathways is not converted to prostaglandins $\mathrm{E}_{2}$ and $\mathrm{F}_{2 a}$ in human skin.

Introduction

We have previously presented evidence for increased amounts of arachidonic acid, prostaglandin $E_{2}$ and $F_{2 a}$-like materials in human skin exudate $24 \mathrm{~h}$ after irradiation with u.v.B (290-320 nm) (Black, Greaves, Hensby \& Plummer, 1978); and u.v.C. (100-290 nm) (Camp, Greaves, Hensby, Plummer \& Warin, 1978). This work supports the view that u.v. irradiation increases prostaglandin-like activity in human skin (Sondergaard \& Greaves, 1970; Snyder \& Eaglstein, 1974a). Confirmation that these agents are increased in u.v.-irradiated skin has now been obtained by quantitative combined gas-liquid chromatography - mass spectrometry (GC-MS) in human skin $24 \mathrm{~h}$ after irradiation by u.v.B and u.v.C.

Non-steroidal anti-inflammatory drugs, such as indomethacin, which inhibit prostaglandin synthetase, delay and decrease u.v.-induced erythema in human skin administered orally (Gruber, Ridolfo, Nickander \& Mikulaschek. 1971) topically or intradermally (Snyder \& Eaglstein, 1974a, b). The effect of indomethacin on the erythema and concentrations of arachidonic acid and prostaglandins $E_{2}$ and $F_{2 a}$ in irradiated skin was therefore studied.

\section{Methods}

\section{Subjects}

Female and male adult human volunteers of an age range $18-73$ years $(48.5 \pm 5.0$ s.e. mean) were irradiated on untanned, clinically normal lower abdominal skin. The subjects, some with localized skin disease, had no history of photosensitivity and were not taking oral antihistamines, corticosteroids or nonsteroidal anti-inflammatory agents. The Institute's Ethical Committee approved and each subject gave prior informed consent.

\section{Irradiation}

Four FS20 Westinghouse sun tubes, major emission $290-320 \mathrm{~nm}$, with an intensity of $430 \mu \mathrm{W} \mathrm{cm} \mathrm{cm}^{-2}$ below $320 \mathrm{~nm}$ and placed $30 \mathrm{~cm}$ from the subject, were used for u.v.B irradiation. Each subject's abdomen was irradiated with three times the minimal erythema dose (MED) on an area of approximately $60 \mathrm{~cm}^{2}$. The u.v.C irradiation was achieved in the same subjects using a Phillips low pressure mercury lamp placed $20 \mathrm{~cm}$ from the skin. Six MEDs of u.v.C. was used in 
an attempt to evoke an erythema approximately equal in intensity to three MEDs of u.v.B. Ninety percent of the output had a wavelength of $254 \mathrm{~nm}$ and an

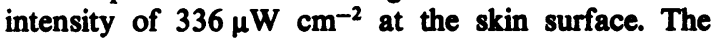
resulting erythema was assessed visually as absent, minimal, moderate or deep red $(0,1,2$ or 3 respectively).

\section{Inflammatory exudate}

Exudate from normal and erythematous skin $24 \mathrm{~h}$ after irradiation was obtained by continuous application of suction at $200 \mathrm{~mm} \mathrm{Hg}$ below atmospheric (Black, Greaves, Hensby, Plummer \& Eady, 1977). In five subjects u.v.B and u.v.C irradiation was repeated after oral indomethacin

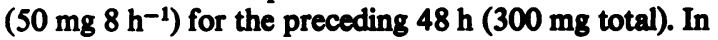
eight subjects exudate was also obtained from two areas which had received topical indomethacin $(3 \mu 1$ $\mathrm{cm}^{-2}, 2.5 \% \mathrm{w} / \mathrm{v}$ in vehicle) or vehicle alone (ethanol : propylene glycol : dimethyl acetamide $19: 19: 2$ by vol.) immediately after u.v.B irradiation.

\section{Photoelectric plethysmographic blood flow measurements}

Blood flow in non-irradiated and in irradiated skin, before and after oral indomethacin, was determined by a photoelectric plethysmographic technique (Ramsay \& Challoner, 1976).

\section{Radioimmunoassay}

Exudate was examined for $\mathrm{PGF}_{2 a}$-like activity using a double antibody radioimmunoassay (RIA) technique modified from the method of Dighe, Emslie, Henderson, Simon \& Rutherford (1975). The antiserum showed minimal cross-reactivity to the 1 and 2 series of prostaglandins $A, B, E$ and $F_{\beta}$, as well as 15 -keto- $\mathrm{PGE}_{2}$ and 15 -keto- $\mathrm{PGF}_{2 a}$. Prostaglandins $D_{1}$ and $D_{2}$ showed approximately $3 \%$ cross-reactivity, while $\mathrm{PGF}_{1 a}$ showed total crossreactivity. The assay could detect 3 pg authentic $\mathrm{PGF}_{2 a^{*}}$

\section{Extraction and thin-layer chromatography}

Exudate $(100 \mu \mathrm{l})$ from individual samples was equilibrated with $100 \mathrm{ng}$ each 3-, 3, 4, 4- tetradeutero PGE $_{2}$ (d4 PGE 2 and 3, 3, 4, 4-tetradeutero PGF $_{2 a}$ (d4 PGF $_{2 a}$ ) and $200 \mathrm{ng} 5,6,8,9,11,12,14,15$ octadeutero arachidonic acid (d8 arachidonic acid) in $1.0 \mathrm{ml}$ of $1.5 \mathrm{mM}$ indomethacin in $95 \%$ aqueous ethanol. Where possible samples were immediately extracted or stored at $-20^{\circ} \mathrm{C}$ prior to extraction.

The exudates, acidified with hydrochloric acid (0.1

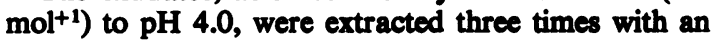
equal volume of redistilled ethyl acetate. The pooled organic phase was dried under reduced pressure and subjected to preparative thin-layer chromatography (t.l.c.) on silica gel $G$ glass backed plates $(100 \times 200 \times 0.25 \mathrm{~mm}$, Anderman) using the FVI solvent system of Anderson (1969). The fractions corresponding to authentic arachidonic acid and prostaglandins $E_{2}$ and $F_{2 a}$ were eluted twice with methanol and dried residues derivatized prior to GCMS.

Preparation of derivatives for gas liquid-chromatography

(a) Methyl esters. Authentic prostaglandins, arachidonic acid and biological samples were vortexed for $60 \mathrm{~s}$ with ethereal methanolic $(9: 1 \mathrm{v} / \mathrm{v})$ diazomethane. The samples were rapidly taken to dryness under a stream of dry air and the methylation step repeated.

(b) Oximation. The methyl ester of authentic $\mathrm{PGE}_{2}$ and the $\mathrm{PGE}_{2}$ zones from the t.l.c. plates were further converted to the corresponding $9-0$-methyl oxime by reacting overnight with $50-100 \mu l$ methyloxime hydrochloride ( $5 \mathrm{mg} \mathrm{ml}^{-1}$ in pyridine). The pyridine was removed under a stream of air.

(c) Trimethylsilylation. The desiccated residues of authentic PGF $_{2 a}$ methyl ester, the $\mathrm{PGF}_{2 a}$ zone and the above oximation products were reacted with $50 \mu l$ $\mathrm{N}, \mathrm{N}$-bis (trimethylsilyl)- tri-fluoroacetamide (BSTFA: Sigma) using the method of Thompson, Los \& Horton (1970).

\section{Combined gas-liquid chromatography-mass spectrometry}

Quantitative multiple ion detection GC-MS was performed using an AEI MS-30 double focusing mass spectrometer interfaced via a membrane separator to a Pye Unicam 104 gas chromatograph. The details of the methods employed are to be published fully elsewhere. Briefly, samples were assayed in triplicate. The column used was a $1.5 \mathrm{~m} \times 2 \mathrm{~mm}$ (i.d.) glass column packed with $1 \%$ OV-1 on Diatomite $(100-120$ mesh; Pye Unicam). The column temperature was $220-250^{\circ} \mathrm{C}$ and the helium flow rate was $25-30 \mathrm{ml}$ $\mathrm{min}^{-1}$.

\section{Solvents and chemicals}

All solvents were analytical grade or redistilled before use. Pyridine, Diazald and methyloxime hydrochloride were obtained from Aldrich. Donkey anti-rabbit precipitating serum was obtained from Wellcome Laboratories, and high specific activity ${ }^{3} \mathrm{H}-\mathrm{PGF}_{2 a}$ from the Radiochemical Centre, Amersham. 
Results

\section{Erythema}

The erythema resulting from exposure to three MED of u.v.B. and six MED of u.v.C reached a maximum at $24 \mathrm{~h}$ at which time exudate samples were obtained (Table 1). Indomethacin given orally reduced the erythema produced by irradiation with u.v.B. and u.v.C. Similarly, topically applied indomethacin reduced u.v.B-induced erythema but the vehicle alone had no discernible effect. The action of topical indomethacin on u.v.C erythema was not tested.

Preliminary results from five subjects using photoelectric plethysmography suggest that, although both u.v.B and u.v.C irradiation produce similar changes in the total blood flow, the erythema is more marked after u.v.B irradiation. Furthermore, oral indomethacin significantly reduced the rise of total blood flow caused by u.v.C but not that caused by u.v.B (Table 1).

\section{Prostaglandin $E_{2}$ and $F_{2 a}$ concentrations}

Twenty-four hours after irradiation by both u.v.B and u.v.C, concentrations of recoverable $\mathrm{PGE}_{2}$ and $\mathrm{PGF}_{2 a}$ were significantly elevated relative to controls (Table 2). The rise was significantly decreased by oral indomethacin following u.v.B and u.v.C irradiation and by topical indomethacin and its vehicle alone after u.v.B irradiation. The results for $\mathrm{PGF}_{2 a}$ obtained by RIA agreed closely with those obtained by GC-MS.

\section{Arachidonic acid concentrations}

Arachidonic acid concentration was raised $24 \mathrm{~h}$ after irradiation with u.v.B and u.v.C. Oral indomethacin caused little rise in arachidonic acid concentrations in irradiated skin although it caused a considerable increase in normal unirradiated skin (Table 2). Concentrations of arachidonic acid in u.v.B irradiated skin following topical indomethacin treatment closely resembled those following oral indomethacin. Unexpectedly, topical application of the vehicle alone suppressed arachidonic acid concentrations in u.v.B. irradiated skin to below those from untreated irradiated skin, although the amounts were still higher than those from normal, non-treated, non-irradiated skin.

\section{Discussion}

The present study confirmed the presence of increased concentrations of arachidonic acid, $\mathrm{PGE}_{2}$ and $\mathrm{PGF}_{2 a}$ in fluid from erythematous human skin irradiated with u.vB or u.v.C. It has been shown that the prostaglandin synthetase inhibitor, indomethacin, given orally or applied topically, completely prevented the increase in prostaglandin activity in u.v.B irradiated skin. Nevertheless, the observation that the inflammatory response to u.v.B irradiation, assessed both visually and by photoelectric plethysmography, was only partially inhibited by indomethacin suggests

Table 1 Visual erythema grade and total blood flow (mean \pm s.e. mean) determined by photoelectric plethysmography (PEP) in control, u.v.B and u.v.C irradiated human skin before and after oral indomethacin.

Control

before 24 h u.v.B $\begin{gathered}\text { after oral } \\ \text { indomethacin }\end{gathered}$

Visual erythema

grade

0

Total blood

flow $t$

(mV)
3

$$
\begin{gathered}
121 \pm 29 \\
n=5 \\
p<0.025
\end{gathered}
$$

2

$$
\begin{gathered}
86 \pm 22 \\
n=5 \\
P<0.05
\end{gathered}
$$$$
P_{s 8}>0.3
$$

before $\begin{gathered}24 \text { hu.v.C } \\ \text { after oral } \\ \text { indomethacin }\end{gathered}$

2

1

$$
\begin{array}{cc}
118 \pm 9 & 60 \pm 15 \\
n=5 & n=5 \\
P<0.005 & P>0.1 \\
& P_{88}>0.02
\end{array}
$$

$\uparrow$ Total blood flow determined by PEP

$P$ values show significance relative to control levels

$P_{s e}$ values show significance relative to $24 \mathrm{~h}$ u.v.-irradiated levels

$n=$ number of samples 


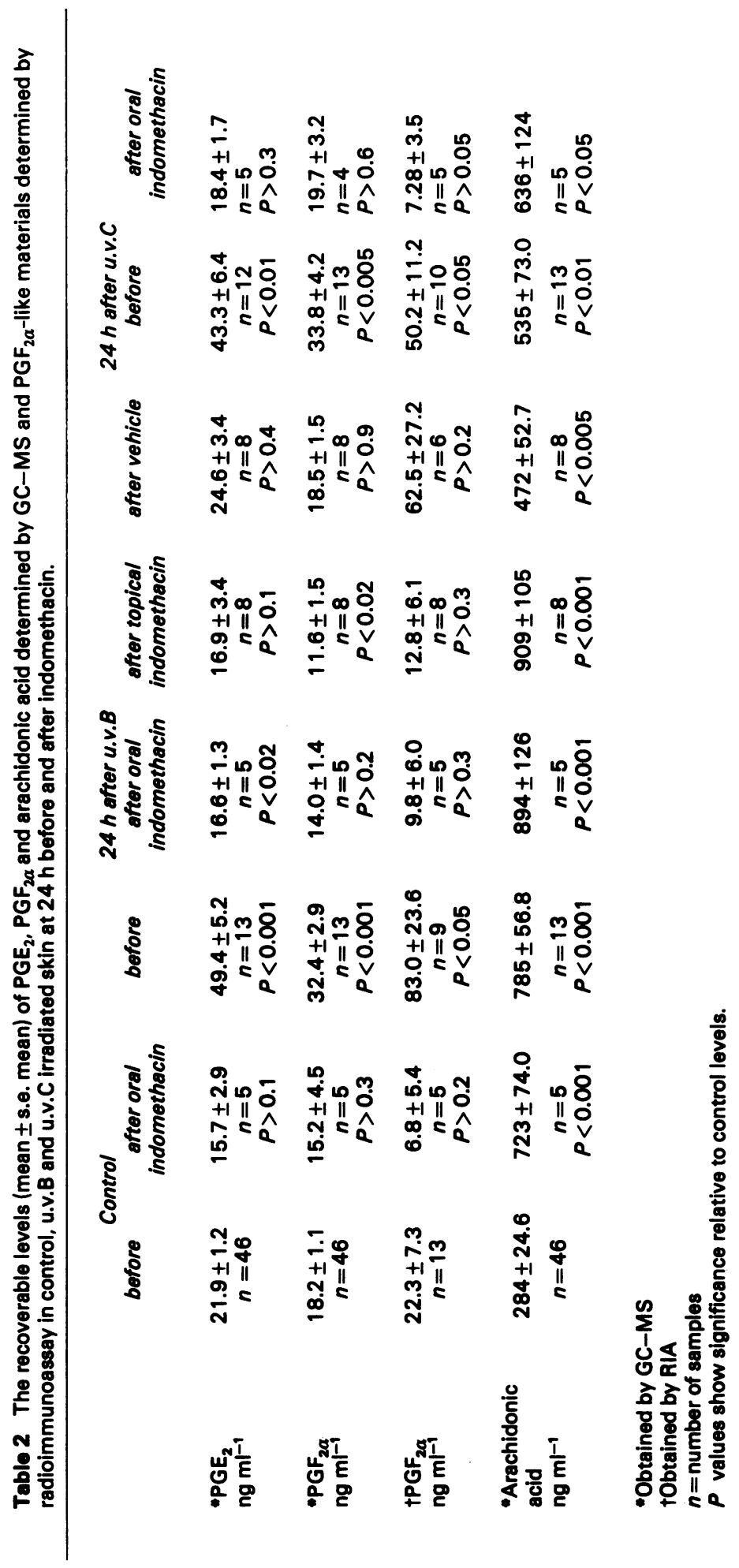


that the vascular changes may be due only in part to activation of cyclo-oxygenase.

Conclusive evidence is presented for the identification of $\mathrm{PGE}_{2}, \mathrm{PGF}_{2 \alpha}$ and arachidonic acid in human skin and for their elevation $24 \mathrm{~h}$ after irradiation with three MED u.v.B and six MED u.v.C. We have previously shown that the maximum increase of prostaglandin-like compounds occurs at approximately $24 \mathrm{~h}$ after three MED u.v.B when the erythema is maximal (Black et al., 1978). Six MED of u.v.C. was chosen in an attempt to obtain a degree of erythema at $24 \mathrm{~h}$ which was comparable with three MED u.v.B. However, it was found that both this and higher doses of u.v.C failed to produce erythema as intense as three MED of u.v.B.

Prostaglandin synthetase inhibitors have previously been shown to inhibit the erythema resulting from u.v. irradiation (Snyder \& Eaglstein, 1974a, b; Miller, Ruderman \& Smith, 1967) and prostaglandins have previously been suggested to mediate this erythema (Greenberg, Eaglstein, Turnier \& Houdek, 1975). However, the possibility that u.v.B but not u.v.C erythema was mediated by prostaglandins has also been proposed to explain the different responses of u.v.B and u.v.C erythema to intradermal indomethacin (Eaglstein \& Marsico, 1975).

We have examined the effects of indomethacin on the erythema, arachidonic acid and prostaglandins $\mathrm{E}_{2}$ and $F_{2 a} 24 h$ after irradiation with u.v.B and u.v.C, when the erythema reaches maximal intensity.

Preliminary results indicate that the elevated total blood flow resulting from u.v.B and u.v.C irradiation is almost identical and confirm the observations of Ramsay \& Challoner (1976). Our findings, following indomethacin treatment, confirm that erythema resulting from u.v.B or u.v.C irradiation is only partially suppressed at $24 \mathrm{~h}$. A comparison of the two reactions in the same subjects suggested that U.v.B was less sensitive than u.v.C erythema to indomethacin. However, the relative proportions of blood flow in the superficial and deep dermal blood vessels may have been altered without any detectable effect on the total blood flow.

Although the intensity of erythema was only partially reduced by indomethacin, the levels of $\mathrm{PGE}_{2}$ and $\mathrm{PGF}_{2 \alpha}$ were reduced to control values in unirradiated skin. At the same time the u.v.-evoked increase in arachidonic acid in irradiated skin was not significantly affected (Table 2). This suggests that neither $\mathrm{PGE}_{2}, \mathrm{PGF}_{2 \alpha}$ nor any other product of the cyclo-oxygenase pathway can alone account for the erythema at $24 \mathrm{~h}$ in response to u.v.B or u.v.C and raises the possibility that, in inflamed skin, indomethacin has resulted in redirection of metabolism of arachidonic acid via the lipoxygenase pathway which in turn has led to formation of nonprostaglandin metabolites which may have vasoactive properties. In contrast, the ability of indomethacin to increase arachidonic acid concentrations markedly in normal unirradiated skin suggests that in this situation arachidonic acid is at least partly metabolised via the cyclo-oxygenase pathway. Since exudate from the same skin showed little or no depression of $\mathrm{PGE}_{2}$ and $\mathrm{PGF}_{2 \alpha}$ other products of cyclo-oxygenase activity including thromboxanes, $\mathrm{PGD}_{2}$ or prostacyclin $\left(\mathrm{PGI}_{2}\right)$ are presumably the major metabolites in healthy skin. Alternatively, the amounts of $\mathrm{PGE}_{2}$ and $\mathrm{PGF}_{2 \alpha}$ in exudate from skin may be low because of rapid turnover.

Suppression of the concentrations of $\mathrm{PGE}_{2}$ and PGF $_{2 \alpha}$ in u.v.B irradiated skin to control levels by the vehicle for dissolving indomethacin is difficult to explain, but the absence of effect on erythema further supports the suggestion that these prostaglandins play no major part in u.v.B-induced erythema.

The results in this paper suggest that the relationships between arachidonic acid metabolism and u.v. erythema are complex, and it is becoming clear that the erythema cannot be explained by variation in concentrations of $\mathrm{PGE}_{2}$ alone. Clearly detailed correlative studies between variation in the concentrations of arachidonic acid and its major metabolites, the degree of inflammation and the action of non-steroid anti-inflammatory drugs will go some way towards solving these problems.

This work was supported by grants from the Medical Research Council, The Wellcome Trust and the Sir Herbert Dunhill Trust. We thank Miss M. Davison and Mr N. Fincham for skilled technical assistance. Grateful thanks are due to Professor E.W. Horton (Edinburgh University) and Drs J. Pike and U. Axen (Upjohn Co.) for their generous gifts of antiserum and prostaglandins respectively. The octadeutero arachidonic acid was a generous gift from Dr R.L. Jones (Edinburgh University).

\section{References}

ANDERSON, N.H. (1969). Preparative thin-layer and column chromatography of prostaglandins. J. lip. Res., 10, 316-319.

BLACK, A.K., GREAVES, M.W., HENSBY, C.N. \& PLUMMER, N.A. (1978). Increased prostaglandins $E_{2}$ and $F_{2 a}$ in human skin at 6 and $24 \mathrm{~h}$ after ultraviolet $B$ irradiation $(290-320 \mathrm{~nm}) . B r$. J. clin. Pharmac., 5, 431-436.

BLACK, A.K., GREAVES, M.W., HENSBY, C.N., PLUMMER, N.A. \& EADY, R.A.J. (1977). A new method for recovery of exudates from normal and inflamed human skin. Clin. exp. Derm., 2, 209-216.

CAMP, R.D., GREAVES, M.W., HENSBY, C.N., PLUMMER, N.A. \& WARIN, A.P. (1978). Irradiation of human skin by short wavelength ultraviolet radiation $(100-290 \mathrm{~nm})$ (u.v.C): increased concentrations of arachidonic acid and 
prostaglandins $\mathrm{E}_{2}$ and $\mathrm{F}_{2 a} . \mathrm{Br}$. J. clin. Pharmac., 6, 145-148.

DIGHE, K.K., EMSLIE, H.A., HENDERSON, L.K., SIMON, L. \& RUTHERFORD, F. (1975). The development of antisera to prostaglandins $B_{2}$ and $F_{2 \alpha}$ and their analysis using solid-phase and double antibody radioimmunoassay methods. Br. J. Pharmac., 55, 503-514.

EAGLSTEIN, W.H. \& MARSICO, A.R. (1975). Dichotomy in response to indomethacin in u.v.-C and u.v.-B induced ultraviolet light inflammation. $J$. invest. Derm., 65, 238-240.

GREENBERG, R.A., EAGLSTEIN, W.H., TURNIER, H. \& HOUDEK, P.V. (1975). Orally given indomethacin and blood flow response to UVL. Arch. Dermatol., 111, 328-330.

GRUBER, C.M., RIDOLFO, A.S., NICKANDER, R. \& MIKULASCHEK, W.M. (1971). Delay of erythema of human skin by anti-inflammatory drugs after ultraviolet irradiation. Clin. Pharmac. Ther., 13, 109-113.
MILLER, W.S., RUDERMAN, F.R. \& SMITH, J.G. (1967). Aspirin and ultraviolet light-induced erythema in man. Arch. Derm., 95, 357-358.

RAMSAY, C.A. \& CHALLONER, A.V.J. (1976). Vascular changes in human skin after ultraviolet irradiation. Br. J. Derm., 94, 487-493

SNYDER, D.S. \& EAGLSTEIN, W.H. (1974a). Intradermal antiprostaglandin agents and sunburn. J. invest. Derm., $62,47-50$.

SNYDER, D.S. \& EAGLSTEIN, W.H. (1974b). Topical indomethacin and sunburn. Br.J. Derm., 90, 91-93.

SONDERGAARD, J. \& GREAVES, M.W. (1970). Pharmacological studies in inflammation due to ultraviolet radiation. J. Path., 101, 93-97.

THOMPSON, C.J., LOS, M. \& HORTON, E.W. (1970). The separation, identification and estimation of prostaglandins in nanogram amounts. Life Sci., 9, 938-988.

(Received August 29, 1977) 